\title{
Effect of inhaled fluticasone on bronchial responsiveness to neurokinin $A$ in asthma
}

\author{
J. Van Schoor, G.F. Joos, R.A. Pauwels
}

\begin{abstract}
Effect of inhaled fluticasone on bronchial responsiveness to neurokinin $A$ in asthma. J. Van Schoor, G.F. Joos, R.A. Pauwels. (C) ERS Journals Ltd 2002.

ABSTRACT: Neurokinin (NK) A causes airway narrowing in patients with asthma through direct and indirect mechanisms. The effects of the inhaled glucocorticosteroid fluticasone propionate (FP) on the bronchial responsiveness to NKA and methacholine were studied.

Patients ( $\mathrm{n}=11$ ) with mild asthma participated in a randomized, double-blind, placebo-controlled crossover trial. FP $(500 \mu \mathrm{g}$ b.i.d) or matched placebo was administered via Diskhaler ${ }^{\mathrm{TM}}$ for 14 days. Bronchial challenges were performed on days 1 and 13 (methacholine) and 0 and 14 (NKA) for each treatment period.

At the active treatment period, the mean $\log _{2}$ provocative concentration causing a $20 \%$ fall in the forced expiratory volume in one second (PC20) \pm SEM for NKA was $-12.72 \pm 0.63$ at the beginning and $-9.77 \pm 0.49$ at the end of the period $(p<0.0001)$, while under placebo, it was $-\mathbf{1 2 . 1 6} \pm 0.82$ and $-12.19 \pm 0.51$ respectively (NS). At the active treatment period, the mean $\log 2 \mathrm{PC} 20$ for methacholine was $-5.25 \pm 0.40$ at the beginning and $-4.22 \pm 0.31$ at the end of the period $(p=0.012)$, while under placebo, it was $-5.47 \pm 0.47$ and $-5.24 \pm 0.42$ respectively (NS). The reduction in response to NKA was significantly larger than that for methacholine.
\end{abstract}

A 2-week course of an inhaled steroid reduces bronchial responsiveness to neurokinin $A$, an effect more pronounced than the reduction in bronchial responsiveness to methacholine.

Eur Respir J 2002; 19: 997-1002.
Dept of Respiratory Diseases, Ghent University Hospital, Ghent, Belgium.

Correspondence: G. Joos, Dept of Respiratory Diseases, 7K12 IE, Ghent University Hospital, De Pintelaan 185, B-9000 Ghent, Belgium.

Fax: 3292402341

E-mail: guy.joos@rug.ac.be

Keywords: Asthma

bronchial challenge

bronchial responsiveness

neurokinin A

neuropeptides

Received: July 252001

Accepted after revision January 19 2002

The present study was supported by GlaxoWellcome plc, UK.
The tachykinins, substance $\mathrm{P}$ and neurokinin (NK) A are potential mediators of asthma. They are produced by sensory airway nerves and nonneural cells, such as endothelial cells, eosinophils, macrophages, and dendritic cells. Substance $P$ and NKA have potent effects on the bronchomotor tone, airway secretion, bronchial circulation (vasodilatation and microvascular leakage) as well as on inflammatory and immune cells $[1,2]$.

Patients with asthma are hyperresponsive to inhaled substance $\mathrm{P}$ and NKA [3, 4]. In vitro studies have revealed that NKA contracts airway smooth muscle directly, by stimulation of tachykinin (NK2) receptors [5]. In patients with asthma the inhalation of tachykinins causes a dose-dependent airway narrowing which is largely preventable by inhalation of nedocromil sodium. Hence inhaled tachykinins act mainly as indirect bronchoconstrictor stimuli [6, 7]. The indirect airway-narrowing effect of the tachykinins is mediated by tachykinin NK1 receptors [8-10].

Glucocorticoids may enhance the expression of neutral endopeptidase, which is the major degrading enzyme of the tachykinins in the airways [11, 12]. Moreover, glucocorticoids are able to reduce the expression of the tachykinin NK1 and NK2 receptors $[13,14]$. The effect of inhaled steroids on the bronchial responsiveness for direct stimuli such as histamine or methacholine is well documented [15]. It is not known whether steroids can affect the bronchoconstrictor response to substance $\mathrm{P}$ or NKA. The aim of the present trial was to study the effects of inhaled steroids on NKA-induced airway narrowing. Moreover the authors wanted to compare the eventual changes in bronchial responsiveness to NKA with those to methacholine. Therefore, airway responsiveness to NKA and methacholine was assessed prior to and following a 2-week course of inhaled fluticasone propionate (FP), $1000 \mu \mathrm{g} \cdot \mathrm{day}^{-1}$, in a group of patients with mild-to-moderate asthma.

\section{Methods}

\section{Patients}

Adult subjects with stable mild-to-moderate asthma [16] were recruited for the trial. They had to be nonsmokers or exsmokers (defined as having a cumulative smoking history of $\leqslant 5$ pack-yrs, and having ceased smoking for at least $1 \mathrm{yr}$ prior to the start of the trial). Females of childbearing potential had to use reliable contraceptives, and pregnant or lactating women were excluded from participation. No relevant concomitant diseases were present. The only treatment allowed during the study consisted of inhaled salbutamol (Ventolin ${ }^{\mathrm{TM}}$; GlaxoWellcome, 
Stockley Park, UK) as reliever medication. Patient nos. 4, 6 and 10 were on inhaled steroids (budesonide $400 \mu \mathrm{g} \cdot \mathrm{day}^{-1}$, budesonide $800 \mu \mathrm{g} \cdot \mathrm{day}^{-1}$ and beclomethasone dipropionate $1000 \mu \mathrm{g} \cdot \mathrm{day}^{-1}$, respectively) and discontinued its use at least 4 weeks prior to the first screening visit. Their morning baseline forced expiratory volume in one second (FEV1) was at least $70 \%$ of the predicted and the provocative concentration causing a $20 \%$ fall in the forced expiratory volume in one second (PC20) at the screening methacholine and NKA challenges was $<8 \mathrm{mg} \cdot \mathrm{mL}^{-1}$ and $1.0 \times 10^{-6} \mathrm{~mol} \cdot \mathrm{mL}^{-1}$, respectively. No patient was studied within 4 weeks of an upper or lower respiratory tract infection or exacerbation of asthma.

The trial protocol was approved by the ethical committee of the Ghent University Hospital. All participants gave their written informed consent.

\section{Study design}

The study was of a randomized, double-blind, placebo-controlled, two-period crossover design. On screening day 1 (visit one), the patients underwent a methacholine challenge. The baseline FEV1 prior to each subsequent challenge had to be within $15 \%$ of the screening baseline FEV1 obtained at visit one. Shortacting $\beta_{2}$-agonists and caffeine-containing foods and beverages had to be withheld for at least $10 \mathrm{~h}$ before each challenge. A NKA challenge on screening day 2 (visit two) was performed 24-72 h later. Study-period one commenced within 10 days after visit two; firstly, a methacholine and a neurokinin-A challenge was performed on days 1 (visit three) and 0 (visit four), respectively. At visit four (day 0), the study medication was handed over to the participants, who started using it from day 1 and for the following 14 days. The study medication consisted of FP (Flixotide ${ }^{\mathrm{TM}}$; GlaxoWellcome, Stockley Park, UK), $2 \times 500 \mu \mathrm{g} \cdot \mathrm{day}^{-1}$ or matched placebo, which was inhaled as a dry powder from a Diskhaler ${ }^{\mathrm{TM}}$ (GlaxoWellcome, Stockley Park, UK). The morning dose was inhaled between 06.00-08.00 $\mathrm{h}$ and the evening dose between 20.00-22.00 h. Following each dose, the mouth was rinsed with tap water, following which the water was spat out. On days 13 (visit five) and 14 (visit six) respectively, the last 2 days of the treatment period, methacholine and NKA challenges were repeated. Following treatment-period one, there was a washout period of 4 weeks \pm 5 days, counted from day 15 , the first day without study medication. After this, the patients crossed over to the other medication in study-period two, which was identical to period one. As in period one, methacholine and neurokinin-A challenges were performed on separate, consecutive days at the beginning (visits seven and eight) and the end (visits nine and ten) of this second treatment period, respectively.

\section{Pulmonary function testing}

Pulmonary function tests were performed using a water-sealed spirometer (Pulmonet III; Sensormedics, Bilthoven, the Netherlands), in accordance with the
European Respiratory Society guidelines [17]. The highest value of three consecutive manoeuvres was accepted for evaluation at each performance. Spirometry was performed with the patient in a sitting position, the nose occluded by a clip. The lungfunction technician and the spirometer were the same throughout the study.

\section{Bronchial challenge tests}

The methacholine challenge was performed by inhaling doubling concentrations of methacholine from a "Wiesbadener Doppel Inhalator" (Wiesbadener Inhalatoren-Vertrieb, Wiesbaden, Germany), until the FEV1 fell by $>20 \%$ of the postdiluent baseline FEV1 of that day, according to the method of CocKCROFT et al. [18]. The methacholine diluent (phosphatebuffered saline (PBS)) and the subsequent methacholine concentrations $\left(2,4,8,16\right.$ and $\left.32 \mathrm{mg} \cdot \mathrm{mL}^{-1}\right)$ were inhaled during 2 min of quiet tidal breathing, in a sitting position, the nose being occluded by a clip. Measurements of FEV1 were performed at 30 and $90 \mathrm{~s}$ after the inhalation of each concentration. The nebulizations of the different concentrations were initiated at 5-min intervals.

NKA challenge was performed by inhaling increasing concentrations of NKA, as described previously [10]. Prior to each NKA challenge, baseline FEV1 was determined. The subjects then inhaled the NKA diluent and FEV1 was measured 3 and 7 min after the start of the inhalation, the lowest value of both being considered as the postdiluent baseline FEV1. The actual NKA challenge was performed provided the FEV1 did not fall by $>10 \%$ after inhaling diluent. During the challenge, increasing concentrations of NKA $\left(3.3 \times 10^{-9}, 1.0 \times 10^{-8}, 3.3 \times 10^{-8}, 1.0 \times 10^{-7}, 3.3 \times 10^{-7}\right.$ and $1.0 \times 10^{-6} \mathrm{~mol} \cdot \mathrm{mL}^{-1}$ ) were inhaled until FEV1 fell by $\geqslant 20 \%$ of its respective postdiluent baseline value.

NKA was obtained from Peninsula (St. Helens, UK) and was diluted in saline containing $1 \%$ human serum albumin (Behringwerke AG, Marburg, Germany). The dilutions of NKA were freshly prepared on the morning of the challenge and kept on ice until nebulization. The aerosols were produced using a Mallinckrodt jet nebulizer [19]. A collapsible 30-L plastic bag, which served as a drying chamber, was filled with nitrogen $\left(\mathrm{N}_{2}\right)$ gas. Then, $0.5 \mathrm{~mL}$ of diluent or each subsequent NKA concentration was sprayed by compressed $\mathrm{N}_{2}$ (4 bar) in $1 \min \pm 10 \mathrm{~s}$ into the drying chamber, in which the droplets rapidly evaporated to dry particles. Finally, the patient inhaled the aerosol from the bag during $2 \mathrm{~min}$ of quiet tidal breathing through a three-way valve and a mouthpiece, until collapse of the bag. Supplementary oxygen (at a flow of $4 \mathrm{~L} \cdot \mathrm{min}^{-1}$, inspiratory oxygen fraction: 0.995) was supplied into the mouthpiece. The patients performed the inhalation in a sitting position, the nose being occluded by a clip. Pulmonary function measurements were performed at 3 and $7 \mathrm{~min}$ after the start of the inhalation of each concentration. The nebulizations of the different concentrations were initiated at 10-min intervals.

All methacholine and NKA challenges were performed in the morning, starting between 08.00-09.00 h. 
After having completed the challenge, the patients were allowed to leave the dept, on the condition that their FEV1 had returned to within $10 \%$ of their prechallenge FEV1 on that day.

\section{Statistical analysis}

The morning FEV1 prediluent baseline values on the different visits were compared by means of an analysis of variance (ANOVA), to test for treatment and carry-over effect.

For the data analysis of the airway responsiveness, the values of PC20 for methacholine and NKA were converted into moles and then $\log 2$ transformed, in order to obtain doubling steps. A PC20 value of $64 \mathrm{mg} \cdot \mathrm{mL}^{-1}$ for methacholine (one doublingconcentration higher than the highest concentration tested), or of $3.3 \times 10^{-6} \mathrm{~mol} \cdot \mathrm{mL}^{-1}$ for NKA (a $0.5 \log 10$ higher concentration than the highest concentration tested) was attributed in those cases where the desired fall in FEV1 was not obtained.

The effect of a treatment on the airway responsiveness was calculated by pairwise comparison of the $\log 2 \mathrm{PC}_{20}$ values at the beginning and end of the respective treatment period, using a paired t-test. This was carried out separately for the methacholine and NKA challenge results.

In order to compare the FP-induced changes in airway responsiveness between NKA and methacholine challenges, the difference between the $\log 2$ PC20 value at the end and the beginning of the FP period, hereafter called $\Delta \log 2$ PC20 (PostFP-PreFP), was calculated for NKA and methacholine separately. The changes obtained for NKA and methacholine (their respective $\Delta \log _{2} \mathrm{PC} 20$ (PostFP-preFP)), were then compared, by means of a paired t-test.

For all analyses, a $p$-value of $<0.05$ was considered significant. Data are expressed as mean \pm SEM.

\section{Results}

\section{Patient characteristics at screening}

Eleven patients, aged 18-49 yrs (mean: $27.5 \mathrm{yrs}$ ), 7 females and 4 males, participated in the trial.
Table 2. - Evolution of the morning baseline prechallenge forced expiratory volume in one second during the trial

\begin{tabular}{lcc}
\hline & Methacholine & NKA \\
\hline Placebo $\rightarrow$ FP sequence & & \\
Screening & & \\
PrePL & $3.26 \pm 0.57$ & $3.20 \pm 0.54$ \\
PostPL & $3.10 \pm 0.54$ & $3.08 \pm 0.56$ \\
PreFP & $3.21 \pm 0.58$ & $3.27 \pm 0.42$ \\
PostFP & $3.28 \pm 0.57$ & $3.27 \pm 0.54$ \\
FP Placebo sequence & $3.56 \pm 0.51$ & $3.52 \pm 0.51$ \\
Screening & $3.12 \pm 0.50$ & \\
PreFP & $3.04 \pm 0.62$ & $3.89 \pm 0.45$ \\
PostFP & $3.32 \pm 0.58$ & $3.24 \pm 0.59$ \\
PrePL & $3.00 \pm 0.47$ & $2.95 \pm 0.48$ \\
PostPL & $2.98 \pm 0.67$ & $3.06 \pm 0.74$ \\
\hline
\end{tabular}

Data are presented as mean \pm SD. FP: fluticasone propionate; PL: placebo; NKA: neurokinin A. ${ }^{\#}$ : patient nos. 1, 2, 6, 7, 9, 11; ๆ: patient nos. $3,4,5,8,10$.

Their mean \pm SEM baseline FEV1 was $3.20 \pm 0.16 \mathrm{~L}$ or $88.0 \pm 3.44 \%$ of the predicted. Their mean screening $\log 2$ PC20 for methacholine was $-5.96 \pm 0.20$, while their mean screening $\log 2 \mathrm{PC} 20$ for NKA was $-12.71 \pm$ 0.63 (table 1).

The effect of treatment on the morning baseline forced expiratory volume in one second values

FP significantly increased the baseline prechallenge FEV1 values, compared to placebo; this was the case for the premethacholine challenge baselines $(p=0.006)$ as well as for the pre-NKA challenge baselines ( $\mathrm{p}=$ 0.027) (table 2). Neither the baseline FEV1, nor the bronchial responsiveness to NKA or to methacholine at the beginning of each treatment period were different, so that a carry-over effect could be ruled out.

The effect of fluticasone propionate on bronchial hyperresponsiveness to neurokinin A

At the active treatment period, the mean $\log 2 \mathrm{PC} 20$ for NKA was $-12.72 \pm 0.63$ at the beginning and $-9.77 \pm 0.49$ at the end of the period $(\mathrm{p}<0.0001)$. The mean $\log 2$ PC20 for NKA was $-12.16 \pm 0.82$ at the

Table 1.-Patient characteristics at screening

\begin{tabular}{lcccccc}
\hline $\begin{array}{l}\text { Patient } \\
\text { no. }\end{array}$ & $\begin{array}{c}\text { Age } \\
\text { yrs }\end{array}$ & Sex & $\begin{array}{c}\text { Baseline } \\
\text { FEV1 L }\end{array}$ & $\begin{array}{c}\text { Baseline } \\
\text { FEV1 \% pred }\end{array}$ & $\begin{array}{c}\text { Log2 PC20 } \\
\text { methacholine }\end{array}$ & $\begin{array}{c}\text { Log2 PC20 } \\
\text { NKA }\end{array}$ \\
\hline 1 & 22 & F & 2.57 & 72.0 & -6.71 & -12.92 \\
2 & 20 & F & 3.56 & 93.9 & -6.51 & -15.65 \\
3 & 32 & M & 3.67 & 90.0 & -5.25 & -16.04 \\
$4^{\#}$ & 28 & F & 3.12 & 97.8 & -5.92 & -14.28 \\
5 & 49 & M & 3.28 & 92.9 & -5.35 & -11.83 \\
$6^{\#}$ & 25 & F & 3.26 & 103.8 & -5.61 & -13.29 \\
7 & 37 & M & 2.85 & 71.3 & -7.06 & -10.30 \\
8 & 23 & F & 2.30 & 90.6 & -6.14 & -10.17 \\
9 & 27 & F & 3.10 & 9.6 & -5.10 & -12.26 \\
$10^{\#}$ & 18 & F & 3.24 & 90.9 & -5.96 & \\
11 & 21 & M & 4.19 & & 9.9 & \\
\hline
\end{tabular}

FEV1: forced expiratory volume in one second; PC20: provocative concentration causing a $20 \%$ fall in the FEV1; NKA: neurokinin A; F: female; M: male. ${ }^{\#}$ : patient stopped inhaled-steroid treatment at least 4 weeks prior to visit one. 


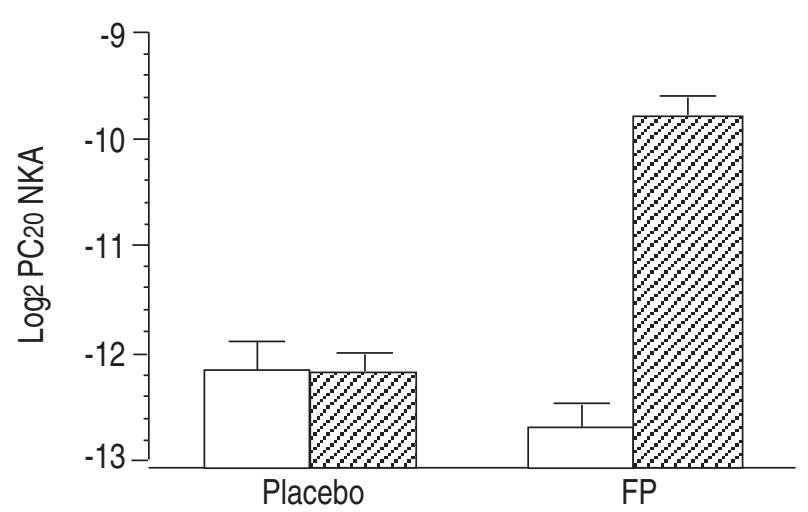

Fig. 1. - Log2 provocative concentration causing a $20 \%$ fall in the forced expiratory volume in one second (PC20) for neurokinin A (NKA) before $(\square)$ and at the end of both treatment periods $(\mathbb{Z})$ (data are presented as mean \pm SEM; $n=11$ ). Post- versus preplacebo: NS; post- versus prefluticasone propionate (FP): $\mathrm{p}<0.0001$.

beginning and $-12.19 \pm 0.51$ at the end of the placebo period (NS) (fig. 1).

The effect of fluticasone propionate on bronchial hyperresponsiveness to methacholine

At the active treatment period, the mean $\log 2 \mathrm{PC} 20$ for methacholine was $-5.25 \pm 0.40$ at the beginning and $-4.22 \pm 0.31$ at the end of the period $(\mathrm{p}=0.012)$. The mean $\log 2$ PC20 methacholine was $-5.47 \pm 0.47$ at the beginning of the placebo period and $-5.24 \pm 0.42$ at the end (NS) (fig. 2).

Comparison of the fluticasone propionate-induced changes in bronchial hyperresponsiveness between neurokinin $A$ and methacholine challenges

The $\Delta \log 2$ PC20 (PostFP-PreFP) was $2.90 \pm 0.47$ for the NKA challenge, and $1.03 \pm 0.34$ for the methacholine challenge $(\mathrm{p}=0.004)$.

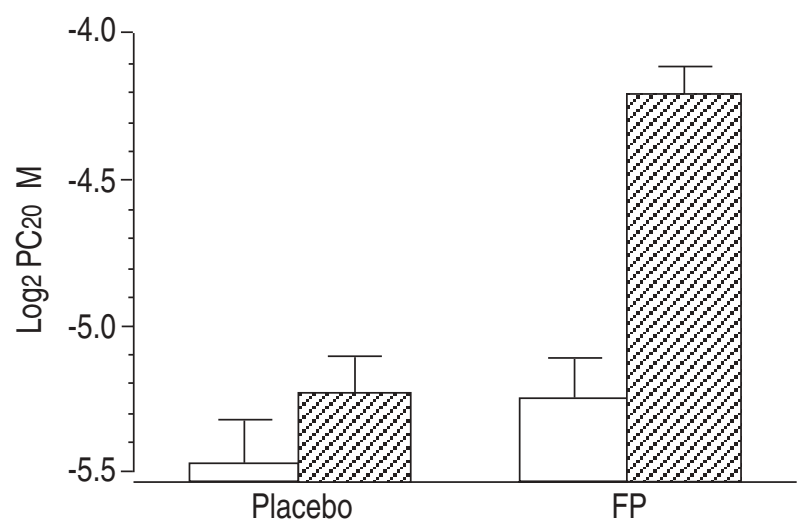

Fig. 2. - Log2 provocative concentration causing a $20 \%$ fall in the forced expiratory volume in one second $\left(\mathrm{PC}_{20}\right)$ for methacholine (M) before $(\square)$ and at the end of both treatment periods $(\mathbb{Z})$ (data are presented as mean \pm SEM; $n=11$ ). Post- versus preplacebo: NS; post- versus prefluticasone propionate (FP): $\mathrm{p}=0.012$.

\section{Discussion}

In this study a 2-week treatment with the inhaled steroid FP reduced bronchial responsiveness to NKA in patients with asthma. The reduction in bronchial responsiveness to NKA was larger than the reduction in responsiveness to methacholine.

The bronchoconstrictor effect of NKA in asthma is well documented [3, 4]. Although NKA contracts airway smooth muscle directly [5] the in vivo bronchoconstrictor effect of inhaled NKA and the related tachykinin substance $\mathrm{P}$ are mainly due to indirect airway-narrowing effects such as stimulation of inflammatory cells [6,7], stimulation of cholinergic nerves [20, 21], and induction of plasma protein extravasation [22]. The effects of inhaled tachykinins are potentiated by inhibitors of the degrading enzyme neutral endopeptidase (NEP) [4].

This study clearly demonstrated that treatment of patients with mild asthma for 14 days with an inhaled steroid reduced the bronchial responsiveness to NKA. Glucocorticosteroids have a very broad spectrum of activity that might explain their therapeutic activity in asthma [23]. Glucocorticosteroids can specifically interfere with the mechanisms involved in the airway response to inhaled tachykinins, by affecting expression of degrading enzymes or by affecting the presence and/or expression of tachykinin receptors. Indeed, several authors have shown that glucocorticosteroids enhance the expression of NEP, the major neuropeptide-degrading enzyme in the airways [11, 12]. Glucocorticosteroids may also affect the number of tachykinin receptors in the airways. They have been shown to reduce tachykinin NK1 [13] and NK2 [14] receptor gene expression. Moreover, by decreasing the number of inflammatory cells carrying the tachykinin NK1 receptor, they could reduce the airway narrowing effects of NKA and substance P [24]. These known effects of glucocorticosteroids on tachykinin action and degradation can at least partially explain the observed decrease in bronchial responsiveness to NKA. Inhaled steroids reduce the inflammatory-cell infiltrate in patients with asthma [25], and by doing so, less cells, for instance mast cells, are available in the airways for interaction with the inhaled tachykinin and for the development of bronchoconstriction.

High doses of inhaled steroids decrease bronchial responsiveness to methacholine and histamine within 2-8 weeks in steroid-naive mild asthmatics; however their effect is limited [26], a finding which was again confirmed in this study (fig. 2). The results of the present study indicate that steroid treatment improved the bronchial responsiveness to NKA to a larger extent than the bronchial responsiveness to methacholine. Indeed treatment with FP for 2 weeks caused a larger shift in responsiveness for NKA than methacholine. Inhaled steroids have previously been shown to have more of an effect on the response to indirect stimuli such as adenosine monophosphate [27, 28], hypertonic saline [29] and exercise [30, 31], than to direct stimuli such as histamine or methacholine. The present findings demonstrated that this was also the case for the indirect bronchoconstrictor agonist NKA.

To conclude, the study demonstrated, for the first 
time that inhaled steroids are able to reduce the bronchial responsiveness to the tachykinin neurokinin A, an effect that was already observed after 2 weeks of treatment. The reduction in bronchial responsiveness to neurokinin A was more pronounced than that for methacholine.

Acknowledgements. The authors would like to thank V. Collart for the lung function measurements and G. Van der Reysen for statistical assistance.

\section{References}

1. Joos GF, Germonpré PR, Pauwels RA. Role of tachykinins in asthma. Allergy 2000; 55: 321-337.

2. Maggi CA. The effects of tachykinins on inflammatory and immune cells. Regul Pept 1997; 70: 75-90.

3. Joos G, Pauwels R, Van Der Straeten M. The effect of inhaled substance $\mathrm{P}$ and neurokinin $\mathrm{A}$ on the airways of normal and asthmatic subjects. Thorax 1987; 42: 779-783.

4. Cheung D, Timmers MC, Zwinderman AH, Den Hartigh J, Dijkman JH, Sterk PJ. Neutral endopeptidase activity and airway hyperresponsiveness to neurokinin $\mathrm{A}$ in asthmatic subjects in vivo. Am Rev Respir Dis 1993; 148: 1467-1473.

5. Advenier C, Naline E, Toty L, et al. Effects on the isolated human bronchus of SR 48968, a potent and selective nonpeptide antagonist of the neurokinin A (NK2) receptors. Am Rev Respir Dis 1992; 146: $1177-1181$.

6. Crimi N, Palermo F, Oliveri R, et al. Effect of nedocromil on bronchospasm induced by inhalation of substance $\mathrm{P}$ in asthmatic subjects. Clin Allergy 1988; 18: 375-382.

7. Joos G, Pauwels R, Van Der Straeten M. The effect of nedocromil sodium on the bronchoconstrictor effect of neurokinin A in subjects with asthma. J Allergy Clin Immunol 1989; 83: 663-668.

8. Naline E, Molimard M, Regoli D, Emonds-Alt X, Bellamy JF, Advenier C. Evidence for functional tachykinin NK1 receptors on human isolated small bronchi. Am J Physiol 1996; 271: L763-L767.

9. Mapp CE, Miotto D, Braccioni F, et al. The distribution of neurokinin-1 and neurokinin-2 receptors in human central airways. Am J Respir Crit Care Med 2000; 161: 207-215.

10. Van Schoor J, Joos G, Chasson B, Brouard R, Pauwels R. The effect of the $\mathrm{NK}_{2}$ receptor antagonist SR48968 (saredutant) on neurokinin A-induced bronchoconstrction in asthmatics. Eur Respir J 1998; 12: 17-23.

11. Borson DB, Gruenert DC. Glucocorticoids induce neutral endopeptidase in transformed human tracheal epithelial cells. Am J Physiol 1991; 260: L83-L89.

12. Sont JK, van Krieken JHJM, van Klink HCJ, et al. Enhanced expression of neutral endopeptidase (NEP) in airway epithelium in biopsies from steroid- versus nonsteroid-treated patients with atopic asthma. Am J Respir Cell Mol Biol 1997; 16: 549-556.

13. Adcock IM, Peters $M$, Gelder C, Shirasaki $H$, Brown CR, Barnes PJ. Increased tachykinin receptor gene expression in asthmatic lung and its modulation by steroids. J Mol Endocrinol 1993; 11: 1-7.

14. Katsunuma T, Mak JCW, Barnes PJ. Glucocorticoids reduce tachykinin $\mathrm{NK}_{2}$ receptor expression in bovine tracheal smooth muscle. Eur J Pharmacol 1998; 344 : 99-106.

15. Barnes PJ. Efficacy of inhaled corticosteroids in asthma. J Allergy Clin Immunol 1998; 102: 531-538.

16. National Institutes of Health NHLBI. Guidelines for the Diagnosis and Management of Asthma. NHLBI publication no. 97-4051. USA, National Institutes of Health, 1997.

17. Sterk PJ, Fabbri LM, Quanjer PH, et al. Airway responsiveness. Standardized challenge testing with pharmacological, physical and sensitizing stimuli in adults. Report Working Party Standardization of Lung Function Tests. European Community for Steel and Coal. Official position of the European Respiratory Society. Eur Respir J 1993; 6: Suppl. 16, 53-83.

18. Cockcroft DW, Killian DN, Mellon JJ, Hargreave FE. Bronchial reactivity to inhaled histamine: a method and clinical survey. Clin Allergy 1977; 7: 235-243.

19. Bel EH, Van Der Veen H, Kramps JA, Dijkman JH, Sterk PJ. Maximal airway narrowing to inhaled leukotriene D4 in normal subjects. Am Rev Respir Dis 1987; 136: 979-984.

20. Joos GF, Pauwels RA, Van Der Straeten ME. The effect of oxitropiumbromide on neurokinin Ainduced bronchoconstriction in asthmatics. Pulmon Pharmacology 1988; 1: 41-45.

21. Crimi N, Palermo F, Oliveri R, et al. Influence of antihistamine (astemizole) and anticholinergic drugs (ipratropium bromide) on bronchoconstriction induced by substance P. Ann Allergy 1990; 65: 115-120.

22. Cheung D, Van Der Veen H, Den Hartigh J, Dijkman JH, Sterk PJ. Effects of substance $\mathrm{P}$ on airway responsiveness to methacholine in asthmatic subjects in vivo. J Appl Physiol 1994; 77: 1325-1332.

23. Barnes PJ. Anti-inflammatory actions of glucocorticoids: molecular mechanisms. Clin Sci 1998; 94: 557-572.

24. Joos GF, Pauwels RA. Pro-inflammatory effects of substance P: new perspectives for the treatment of airway diseases? Trends Pharmacol Sci 2000; 21: 131-133.

25. Djukanovic R, Wilson JW, Britten KM, et al. Effect of an inhaled corticosteroid on airway inflammation and symptoms in asthma. Am Rev Respir Dis 1992; 145: 669-674.

26. van Grunsven PM, van Schayck CP, Molema J, Akermans RP, van Weel C. Effect of inhaled corticosteroids on bronchial responsiveness in patients with "corticosteroid naïve" mild asthma: a metaanalysis. Thorax 1999; 54: 316-322.

27. $\mathrm{O}^{\prime}$ Connor BJ, Ridge SM, Barnes PJ, Fuller RW. Greater effect of inhaled budesonide on adenosine 5'monophosphate- induced than on sodium-metabisulfiteinduced bronchoconstriction in asthma. Am Rev Respir Dis 1992; 146: 560-564.

28. Doull L, Sandall D, Smith S, Schreiber J, Freezer NJ, Holgate ST. Differential inhibitory effect of regular inhaled corticosteroid on airway responsiveness to adenosine $5^{\prime}$ monophosphate, methacholine, and bradykinin in symptomatic children with recurrent wheeze. Pediatr Pulmonol 1997; 23: 404411. 
29. Du Toit JI, Anderson SD, Jenkins CR, Woolcock AJ, Rodwell LT. Airway responsiveness in asthma: bronchial challenge with histamine and $4.5 \%$ sodium chloride before and after budesonide. Allergy Asthma Proc 1997; 18: 7-14.

30. Pedersen S, Hansen OR. Budesonide treatment of moderate and severe asthma in children: a dose-response study. J Allergy Clin Immunol 1995; 95: 29-33.

31. Hofstra WB, Neijens HJ, Duiverman EJ, et al. Doseresponses over time to inhaled fluticasone propionate treatment of exercise- and methacholine-induced bronchoconstriction in children with asthma. Pediatr Pulmonol 2000; 29: 415-423. 